\title{
Technical Advances and Strategies for Future Developments in Mechanization
}

\author{
James L. Glancey ${ }^{1}$, Edwin Kee ${ }^{2}$, and Tracy Wootten ${ }^{2}$
}

ADDITIONAL INDEX wORDs. harvesting, mechanization, vegetables

\begin{abstract}
SUMMARY. The vegetable industry is important to our nation as a provider of nutritious and safe food directly consumed by our citizens. It is also critical to a rich and vigorous national agriculture. During the 20th century, engineering innovations coupled with advances in genetics, crop science, and plant protection have allowed the vegetable industry in the U.S. to plant and harvest significantly more land with higher yields while using less labor. Currently, fresh and processed vegetables generate $16 \%$ of all U.S. crop income, but from only $2 \%$ of the harvested cropland. Yet, many of the challenges in production that existed a century ago still exist for many crops. Perhaps the most significant challenge confronting the industry is labor, often accounting for $50 \%$ of all production costs. A case study of the mechanized production system developed for processed tomatoes (Lycopersicon esculentum) confirms that systematic methodology in which the machines, cultural practices, and cultivars are designed together must be adopted to improve the efficiency of current mechanized systems as well as provide profitable alternatives for crops currently hand-harvested. Only with this approach will horticultural crop production remain competitive and economically viable in the U.S.
\end{abstract}

\section{Status of mechanization in the U.S.}

A gricultural mechanization has allowed growers in the U.S. to plant and harvest significantly more land with higher yields while using less labor. In recognition of this, the National Academy of Engineers ranked the 20 greatest engineering achievements of the last 100 years. The accomplishments included electrification, television, automobiles, and computers; agricultural mechanization was ranked seventh. Mechanization was, by the end of the century, partly responsible for improving the quality of diets around the world while lowering food costs. In addition to the often-cited examples of the tractor and grain combine, several significant developments were directly attributable to vegetable production. These include precision planters; harvesters for potato (Solanum tuberosum), tomato, and pickling cucumber (Cucumis sativus); and mobile threshing units for pea (Pisum sativum) and bean (Phaseolus spp.).

Currently almost all horticultural

University of Delaware, Newark, DE 19717

${ }^{1}$ Department of Bioresources Engineering. To whom reprint requests should be addressed; e-mail address: jglancey@udel.edu

${ }^{2}$ Department of Plant and Soil Sciences and the Delaware Cooperative Extension Service. crop production benefits from some aspect of mechanization, whether it be tillage, planting, chemical application, and/or harvest. Table 1 lists crops that currently utilize mechanized harvest systems. In 2002, thirty-three major vegetables and potatoes were produced on 3.67 million acres (1.485 million ha), and $29 \%$ of the total was mechanically harvested (Table 2). However, only $17 \%$ of fresh market vegetables utilize mechanical harvest, while virtually $100 \%$ of potatoes and $96 \%$ of the major processing crops are machine harvested (U.S. Department of Agriculture, 2002). These percentages do not represent various harvest aids or in-field packing systems, only crops removed from the plant by machine. It is important to note that while producers of many vegetable crops do enjoy the benefits of these systems, current systems would benefit from design and operation improvements that improve efficiency and, in some cases, increase very marginal profits.

Despite the advances in mechanized production of several commodities, harvest and separation mechanisms still need to be designed and tested for many crops. Given the labor-intensive nature of hand harvesting, this deficiency often translates to a large seasonal workforce and high harvest costs. The absence of mechanical harvesting technology exists for many fresh market crops, like melon (Cucumis melo), pepper (Capsicum annuum), squash (Cucurbita maxima), and staked tomato production systems, as well as several processing crops.

Several technological and strategic opportunities have the potential to enhance the vegetable industry as it continues to evolve in the 21 st century. Short-term, intelligent machines capable of operating with minimal operator inputs will provide U.S. growers with rapid and accurate planting, high-speed post-planting operations, and improved harvest efficiency. Although the economic and environmental advantages are still uncertain, site-specific technologies may provide a means to improve the production of several vegetables once sufficient yield and soil data become available. These technologies, coupled with new harvest technologies and advances in crop production and cultivars, may offer significant reductions in harvest labor.

\section{Labor and global issues}

Since the end of World War II, the number of farm workers has declined as technology has advanced (Martin, 2003). Agricultural employment represents $2.7 \%$ of total civilian employment

Table 1. Vegetable crops currently harvested mechanically.

Fresh market

Celery (Apium graveolens var. dulce)

Lettuce (Latuca sativa)

Spinach (Spinacia oleracea)

Squash (Cucurubita maxima)

Sweet corn (Zea mays var. saccharata)

Root, bulb and tuber crops ${ }^{\mathrm{z}}$

Beet (Beta vulgaris)

Carrot (Daucus carota var. sativa)

Dry onion (Allium cepa)

Garlic (Allium satioum)

Potato (Solanum tuberosum)

Radish (Raphanus sativus)

Sweetpotato (Ipomea batatas)

Turnip (Brassica rapa)

Processing crops

Green bean (Phaseolus vulgaris)

Lima bean (Phaseolus lunatus)

Pea (Pisum sativum)

Pepper (Capsicum annuum)

Pickling cucumber (Cucumis sativus)

Rhubarb (Rheum rhaponticum)

Spinach

Sweet corn

Tomato (Lycopersicon esculentum)

${ }^{2}$ Utilized as fresh or processed. 
Table 2. Fresh market and processing crop production and harvest method of the 33 major vegetables grown in the U.S.

\begin{tabular}{lccc}
\hline Crop & $\begin{array}{c}\text { Land in } \\
\text { production } \\
(\text { acres })^{\mathrm{z}}\end{array}$ & $\begin{array}{c}\text { Hand } \\
\text { harvested } \\
(\%)\end{array}$ & $\begin{array}{c}\text { Machine } \\
\text { harvested } \\
(\%)\end{array}$ \\
\hline $\begin{array}{l}\text { Processing } \\
\text { Fresh market }\end{array}$ & $1,272,000$ & 4 & 96 \\
$\quad \begin{array}{l}\text { Potato } \\
\quad \text { All other vegetables }\end{array}$ & $1,300,000$ & 0 & 100 \\
Total & $1,101,820$ & 94 & 6 \\
\hline acre $=2.4711$ ha & $3,673,820$ & 28 & 72 \\
\hline
\end{tabular}

in the U.S. (Findeis, 1998). Ironically, while hired farm workers as a percentage of the total agricultural work force (30\%) have increased since 1945 , they make up less than $1 \%$ of all U.S. wage and salary earners. The remaining $70 \%$ of the agricultural work force includes farm operators and unpaid family workers. The U.S. census reports 878,000 hired farm workers in 2001, yet Martin at University of California, Davis (UCDavis) reports 2.5 million workers, of which 1.8 million are estimated to work on crop farms. Fifty-eight percent of these crop workers are thought to be unauthorized.

Hired farm workers are the lowest paid full-time workers in the U.S. Twelve percent of U.S. farm workers are migrant workers, although in some regions it may be as high as $75 \%$. Agricultural labor and immigration policies that support inexpensive, migratory/seasonal labor from foreign sources create a readily available labor pool for the production and harvest of vegetable crops. Hiring migrant labor, while often critical to the production and harvest of the crop, comes with direct and indirect costs for the producer. Wage costs have increased over the past three decades. The declining availability of labor, an issue compounded by social and political controversy associated with migratory labor adds to costs associated with harvest labor. Increased regulatory pressures, negative connotations associated with hiring migrant labor, and increased liability issues related to hiring migrant labor add to the cost of labor (Runyan, 2000). Despite these issues, immigrants, especially from Central America and Mexico, are increasingly evident in the agricultural and general labor pool.

In countries currently developing sustainable production systems that will supply the U.S., the emphasis is on lowcost mechanization as a replacement for animal power and hand harvesting. In developing or developed agricultural systems, the need to reduce labor costs is critical for sustaining profitable vegetable production systems.

Producers of vegetable crops, especially of those crops that do not utilize a mechanized harvest system, face not only increasing labor costs, but also foreign competition from regions where labor costs are lower, or where the product is available during off-season in the U.S. For example, the U.S. pickling cucumber industry imports nearly $15 \%$ of their raw product from off-shore sources. While harvest labor wage rates are significantly cheaper in those regions (Mexico, Central America, and India) with transportation and other factors, the imported product is not cheaper than domestic production. The rationale for imports lies with availability of the product during the U.S. winter season to reduce fixed overhead costs by keeping manufacturing plants operating, and utilizing primarily small, gherkin pickles in sizes generally unavailable from U.S. producers. Perhaps a mechanical harvester dedicated to small pickling cucumber harvest would keep this segment of business in the hands of U.S. growers.

The implementation of any agricultural mechanization system competes economically with hired farm labor. This is true whether is the labor is hired in the U.S., or if the labor is working in foreign countries. Mechanization and automation can only be considered as a logical alternative to hand labor when it is economically viable, provides an acceptable level of vegetable quality, and offers consistent cost savings and efficiencies.

\section{The nature of mechanization}

Producers implementing mechanized harvest are trading annual labor costs for capital expenses. There are three major components of a mechanized harvest system: cultivars adapted to mechanized harvest, cultural practices that facilitate the system, and the harvester. An associated component is the subsequent handling and processing of the product.

Issues exist with each component; those associated with mechanical harvesters include recovery, separation, cleaning, and damage of the raw product. Cultivars with profitable yield potential, a concentrated fruit set, plant architecture conducive to mechanical harvest, disease resistance, and acceptable market or processing characteristics must be developed as part of a mechanized harvest system. Mechanized harvest systems are best implemented when production systems adapted to facilitate efficient operation of the machine, including soil preparation, plant populations, cultivation, and levelness of the field, are present. Historically, resolution of these critical issues associated with each component has led to pioneering advances in production systems adapted for mechanized harvest.

\section{A case study:}

\section{Processed tomato production}

Mechanized harvest of processing tomatoes is one of the great success stories of mechanized agriculture. In 1963, mechanized harvesting was utilized on $1.5 \%$ of the processing tomato production in California. By 1966, $75 \%$ of production was mechanically harvested; 2 years later the figure rose to $90 \%$. At that time, California produced $70 \%$ of the nation's processing tomatoes. In 1968, while California was harvesting $90 \%$ of its crop mechanically, only $5 \%$ of the remainder of the U.S. crop was harvested by machine. Today, California produces over $90 \%$ of the U.S. processing tomato crop, and virtually the entire crop in the U.S. is machine harvested. This production represents $45 \%$ of the world's processing tomato crop.

The mechanization of vegetable production involves three major components-a machine system, cultural practices, and cultivar development. In the case of processing tomatoes, all three components benefited from research and development. Engineers at UC-Davis, starting in 1950, began development of the forced balance shaker mechanism to separate the tomato fruit from the vine. Horticultur- 
ists at the same institution developed growth regulator systems (ethylene) to force the tomatoes to mature at the same time while also developing tomato cultivars that tended to ripen uniformly, have thick skins and flesh to withstand bruising and damage, resist cracking at the stem end, and possess various characteristics conducive for processing (high viscosity, small stem scar, small seed locules) (Cargill and Rossmiller, 1969).

While these developments reached commercial fruition in the 1960 s, their origin was a direct response to labor issues. As was later observed:

"Traditionally, California has depended on imported labor to harvest vegetable crops. It began with the Chinese coolie. This was followed by the Japanese, Italians and Portuguese, Hindus, Filipinos, and finally the Braceros. In 1942, realizing that California would soon run out of nationalities to harvest the crops, the University began to develop a tomato that could be harvested mechanically" (Cargill and Rossmiller, 1969).

The first tomato cultivar for mechanized harvest was released in 1962, 19 years after the initiation of the program. Simultaneous work during that time also resulted in the harvester and cultural practices adapted to a mechanized harvest system. Industry cooperation in each component, coupled with cooperative extension educational efforts, enhanced the development process and facilitated commercialization of the total system at the farm level.

\section{Strategies for future developments}

It can be said the issues today are not unlike those that researchers at UC-Davis identified in 1942. The U.S. growers' ability to remain profit- able, operate in an economically viable industry, and compete in the worldwide marketplace depend, in part, on increasing mechanization, especially harvest. The consequences of not developing mechanization technology that reduces the industry's dependence on hand labor will likely be continued migration of production to countries with lower labor costs.

In order to address the critical issue of mechanization development and its implications on the future of horticultural production in the U.S., a national consensus on research and development priorities needs to be reached. In this process, several key issues would need to be addressed, including: setting the priorities for such an iniative; identification of the necessary resources to conduct and implement research; and developing partnerships between appropriate academic, industry, and government entities.

Perhaps an industry-wide discussion on the potential and priorities for vegetable crop harvest mechanization needs to commence. At least five determining factors would need to be considered in identifying the priorities and strategies for future research and development:

- The total land in production and value of the crop need to be considered to evaluate the scope, economic impact, and justification of research investment of a new and/or improved mechanized production system.

- The nature of the crop, its utilization as a final product (fresh or processed), and its suitability or adaptability for mechanical harvest. Some crops may need to be eliminated from practical consideration.

-Identification of crops that currently rely on the most hand labor, and the potential economic benefits of mechanization profitability.

- Consideration of crops that have nutritional or health assets that may benefit the national and world food supply.

-Analysis of the resources required to develop viable production systems, the scientific and engineering expertise need to accomplish this effort, and industry partnerships that would be necessary to deliver this technology to end users.

As was the case with processed tomato production, a philosophy in which the machines, cultural practices, and cultivars are designed together, must be adopted to improve the efficiency of current mechanized systems as well as provide profitable alternatives for crops currently hand harvested. Only with this multidisciplinary approach will horticultural crop production remain competitive and economically viable in the U.S.

\section{Literature cited}

Cargill, B.F. and G.E. Rossmiller (eds.). 1969. Fruit and vegetable harvest mechanization-Technological implications, RMS Rpt. 16, Rural Manpower Ctr., Michigan State Univ., East Lansing.

Findeis, J.L. 1998. Transformation of the U.S. rural labor force: Changes in occupation and industry, p. 54-96 In: T.S. Smith (ed.). Innovations in rural rehabilitation: A modern perspective. Bow River Publ., Arnaudville, La.

Martin, P. 2003. Promise unfulfilled: Unions, immigration, and the farm workers. Cornell Univ. Press, Ithaca, N.Y.

Runyan, J.L. 2000. Profile of hired farm workers, 1998 annual averages. U.S. Dept. Agr., Econ. Res. Serv., Agr. Econ. Rpt. No. 790.

U.S. Department of Agriculture. 2002. Key topics: Vegetable and melons. 5 Feb. 2002. $<$ www.era.usda.gov/topics/view>. 